University of Nebraska - Lincoln

DigitalCommons@University of Nebraska - Lincoln

Finance Department Faculty Publications

Finance Department

6-2009

\title{
The Predictive Content of Aggregate Analyst Recommendations
}

John S. Howe

University of Missouri - Columbia, HoweJ@Missouri.edu

Emre Unlu

University of Nebraska-Lincoln, emre@unl.edu

Xuemin (Sterling) Yan

University of Missouri - Columbia, yanx@missouri.edu

Follow this and additional works at: https://digitalcommons.unl.edu/financefacpub

Part of the Accounting Commons, Corporate Finance Commons, and the Finance and Financial Management Commons

Howe, John S.; Unlu, Emre; and Yan, Xuemin (Sterling), "The Predictive Content of Aggregate Analyst Recommendations" (2009). Finance Department Faculty Publications. 25.

https://digitalcommons.unl.edu/financefacpub/25

This Article is brought to you for free and open access by the Finance Department at DigitalCommons@University of Nebraska - Lincoln. It has been accepted for inclusion in Finance Department Faculty Publications by an authorized administrator of DigitalCommons@University of Nebraska - Lincoln. 
Published in Journal of Accounting Research 47:3 (June 2009), pp. 799-821; doi: 10.1111/j.1475-679X.2009.00337.x Copyright (C) 2009 University of Chicago on behalf of the Institute of Professional Accounting, 2009; published by Accounting Research Center (ARC) at the University of Chicago Booth School of Business in partnership with Wiley-Blackwell. Used by permission.

This is an Accepted Article that has been peer-reviewed and approved for publication in the Journal of Accounting Research. Please cite this article as an "Accepted Article"; doi: 10.1111/j.1475-679X.2009.00337.x

\title{
The Predictive Content of Aggregate Analyst Recommendations
}

\author{
John S. Howe, University of Missouri \\ Emre Unlu, University of Nebraska-Lincoln \\ Xuemin (Sterling) Yan, University of Missouri \\ Corresponding author - X. Yan, 427 Cornell Hall, Columbia, MO 65211-2600; \\ tel (573) 884-9708, fax (573) 884-6296, email yanx@missouri.edu
}

\begin{abstract}
Using more than 350,000 sell-side analyst recommendations from January 1994 to August 2006, this paper examines the predictive content of aggregate analyst recommendations. We find that changes in aggregate analyst recommendations forecast future market excess returns after controlling for macroeconomic variables that have been shown to influence market returns. Similarly, changes in industry-aggregated analyst recommendations predict future industry returns. Changes in aggregate analyst recommendations also predict one-quarter-ahead aggregate earnings growth. Overall, our results suggest that analyst recommendations contain market- and industry-level information about future returns and earnings.
\end{abstract}

\section{Introduction}

This paper provides additional evidence on the information content of analyst recommendations. Our principal research question is whether changes in aggregate analyst recommendations have predictive content for future aggregate (i.e., market and industry) returns and earnings. The study is important because, as argued by Mi-

\footnotetext{
The authors thank Leslie Boni, Paul Brockman, Mike Finke, Grace Hao, Inder Khurana, Xiumin Martin, Brett Olson, Reynolde Pereira, Andy Puckett, Maria Schutte, Ken Shaw, Douglas Skinner (the editor), James Weston, an anonymous referee, and seminar participants at the University of Missouri and the 2007 American Finance Association Annual Meetings for helpful comments. They also thank I/B/E/S for providing us the analyst recommendation data.
} 
chaely and Womack [2005], analysis of decision-making by security analysts, specifically decisions by sell-side analysts to issue recommendations, provides evidence on some of the most fundamental questions in capital markets research. We show that changes in aggregate analyst recommendations forecast future aggregate returns and earnings growth. Our results suggest that, in making recommendations, analysts use an information set that includes market- and industry-level information as well as firm-specific information.

Prior studies focus on the information content of analyst recommendations at the firm level. Womack [1996] finds that upgrades (downgrades) in analyst recommendations are associated with positive (negative) abnormal returns around and after their announcements. Barber, Lehavy, McNichols, and Trueman [2001] show that a strategy of buying stocks with the most favorable recommendations and shorting stocks with the least favorable recommendations yields abnormal gross returns. Jagadeesh, Kim, Krische, and Lee [2004] show that changes in analyst recommendations are robust predictors of future (individual) stock returns. Overall, these studies document that analyst recommendations convey useful firm-specific information. ${ }^{1}$

We analyze the information content of aggregate analyst recommendations. An individual firm's stock price reflects market-level, industry-level, and firm-specific information. If analyst recommendations are based solely on firm-specific information, then we would expect no significant relation between aggregate analyst recommendations and either market or industry returns and earnings. However, if analysts' stock recommendations are partly based on market- or industry-level information, then we would expect aggregate analyst recommendations to predict future market and industry returns and earnings.

Using I/B/E/S sell-side analyst recommendations for U.S stocks from 1994 to 2006, we construct an aggregate analyst recommendation measure-the change in the average analyst ratings across all stocks and analysts. This aggregation cancels out the idiosyncratic components of analyst recommendations and isolates their common response to systematic factors.

We begin by examining the predictive content of aggregate analyst recommendations at the market level. We find that changes in aggregate analyst recommendations predict future market excess returns. In particular, a favorable change in aggregate analyst recommendations forecasts high market excess returns one quarter ahead. The results are statistically significant at the one percent level, and robust to the inclusion of macroeconomic variables that have been shown to influence market returns.

Next, because analysts typically specialize by industry (Boni and Womack [2006]), we investigate the predictive content of industry-aggregated analyst recom-

1. Elton, Gruber, and Grossman [1986], Stickel [1995], and Asquith, Mikhail, and Au [2005] also find significant information content in analyst recommendations. Boni and Womack [2006] show that the information content of analyst recommendations is enhanced within industries. 
mendations. We find modest evidence that industry-aggregated analyst recommendations forecast industry returns. Specifically, current quarter changes in industry-aggregated analyst recommendations are positively related to industry returns over the next quarter. This finding suggests that analyst recommendations contain industry information. Our finding is consistent with Piotroski and Roulstone [2004] who report that analysts increase the amount of industry-level information in stock prices.

Campbell [1991] and Vuolteenaho [2002] show that unexpected returns can be decomposed into two components: (1) changes in expectations about future cash flows (cashflow news); and (2) changes in expectations about future discount rates (expected-return news). ${ }^{2}$ To provide insight into the channel through which aggregate analyst recommendations predict returns, we next examine whether changes in aggregate analyst recommendations predict future aggregate earnings growth.

We follow Kothari, Lewellen, and Warner [2006], Sadka [2007], and Sadka and Sadka [2007] and construct five measures of aggregate earnings growth, including aggregate earnings changes scaled by aggregate market value of equity, aggregate book value of equity, or aggregate earnings, and equal- or value-weighted average of firm-level price scaled earnings changes. We find modest evidence that aggregate analyst recommendations are positively associated with one- quarter-ahead aggregate earnings growth. At the market level, the regression coefficient is positive for all five measures of aggregate earnings growth, and is statistically significant at the ten percent level for four out of five measures. Industry-aggregated analyst recommendations positively and significantly (at the five percent level) predict one-quarter-ahead industry- aggregated earnings growth for all five measures. These results suggest that aggregate analyst recommendations contain earnings information, and that this information is an important reason why aggregate analyst recommendations predict aggregate returns.

Overall, we provide evidence that changes in aggregate analyst recommendations have predictive content for future aggregate returns and earnings. We interpret this evidence as suggesting that the information set that analysts use to make their recommendations includes market- and industry-level information. Further, the predictive content of changes in aggregate analyst recommendations suggests that the market is slow to assimilate new information. This finding is consistent with prior evidence that investors underreact to changes in analyst recommendations at the firm level. Specifically, Stickel [1995], Womack [1996], Barber, Lehavy, McNichols, and Trueman [2001] document that returns for stocks upgraded (downgraded) continue to increase (decrease) for several months after the recommendation change.

2. Many studies in the finance and accounting literature, including Vuolteenaho [2002], Callen and Segal [2004], Callen, Hope, and Segal [2005], Hecht and Vuolteenaho [2006], Sadka [2007], and Sadka and Sadka [2007] have used the variance decomposition approach of Campbell [1991]. 
Our study makes three contributions. First, it expands the literature on analyst recommendations. Prior studies focus almost exclusively on the information content of analyst recommendations at the firm level. In contrast, we examine the predictive content of changes in aggregate analyst recommendations and present evidence that analyst recommendations contain market- and industry-level information. This approach complements existing literature about the role of analysts and sheds additional light on the information content of analyst recommendations.

Second, our study adds to the recent literature on the relation between aggregate earnings and returns. Kothari, Lewelllen, and Warner [2006] find the puzzling result that market returns are negatively related to concurrent aggregate earnings surprises. They argue that this negative earnings-return relation arises because earnings and discount rates move together over time. Sadka and Sadka [2007], however, show that Kothari, Lewelllen, and Warner's finding is driven by the negative correlation between aggregate earnings growth and expected returns (at the beginning of the period). Specifically, investors demand a low risk premium when they expect high aggregate earnings growth. We examine the predictive content of aggregate analyst recommendations for both aggregate returns and aggregate earnings growth, thereby providing additional insight into the relation between aggregate earnings and returns. Specifically, our findings that changes in aggregate analyst recommendations predict both market returns and aggregate earnings suggest that market returns and aggregate earnings are positively correlated in our sample period.

Third, this paper parallels a growing literature on the predictive content of aggregate managerial actions. Seyhun [1988, 1992] and Lakonishok and Lee [2001] show that aggregate insider trading predicts future market movements. Baker and Wurgler [2000] find that the share of equity issues in total new equity and debt issues is a predictor of U.S. stock market returns. Anilowski, Feng, and Skinner [2007] examine the information content of aggregate earnings guidance and document evidence that aggregate guidance, especially downward guidance, is associated with market returns. Finally, Hirshleifer, Hou, and Teoh [2007] find that the level of aggregate accruals is a predictor of market returns. Our study is related to but also distinct from these studies. Like these studies, we aggregate decisions made at the firm level and examine whether they have collective predictive ability for aggregate returns. Unlike these studies, we examine decisions made by market participants who are not firm insiders. We thus provide further evidence of the predictive content of aggregated decisions by individual market participants.

The rest of this paper proceeds as follows. Section 2 describes the data and our aggregate analyst recommendation measure. Section 3 investigates whether aggregate analyst recommendations predict future aggregate returns. Section 4 examines whether aggregate analyst recommendations predict future aggregate earnings growth. Section 5 concludes. 


\section{Data, Descriptive Statistics, and Aggregate Analyst Recommendations}

\subsection{Data And Sample}

Our initial sample consists of all analyst recommendations for U.S stocks in the I/B/E/S Analyst Recommendation Detail History file for the period from January 1994 to August 2006. I/B/E/S codes recommendations from 1 (strong buy) to 5 (sell). Following many prior studies, we reverse the ordering so that larger numbers indicate more favorable recommendations.

In order to be included in our final sample, a recommendation must satisfy the following criteria: (1) the recommendation must be associated with a CUSIP number and have a recommendation date; (2) the recommendation must be made by an analyst with a non-missing analyst code; (3) the firm must be in the Center for Research in Security Prices (CRSP) database during the month of recommendation; and (4) the firm must have a share code of 10 or 11 and a non-missing SIC code on CRSP.

We obtain value-weighted market returns and selected firm characteristics including share price, shares outstanding, and SIC code from CRSP. We match stocks in the I/B/E/S database to the CRSP database using 8-digit CUSIP numbers. We obtain quarterly earnings and book value of equity from Compustat. We use firms' SIC codes from CRSP to group stocks into the 48 industries of Fama and French [1997]. We obtain the monthly value-weighted Fama- French industry portfolio returns from Kenneth French's website. ${ }^{3}$

We obtain three-month Treasury bill rates, 10-year Treasury bond yields, and Moody's Baa corporate bond yields from the Federal Reserve Bank of St. Louis. ${ }^{4}$ We calculate term spread as the difference between the long-term government bond yield and the 3-month Treasury bill rate. We calculate default spread as the difference between Moody's Baa corporate bond yield and the10-year Treasury bond yield. We obtain monthly dividend yields for the S\&P 500 index from Amit Goyal's website. ${ }^{5}$

\subsection{Descriptive Statistics For Analyst Recommendations}

After applying the filters to the I/B/E/S Detail History file for U.S. firms during the period 1994-2006, we obtain a final sample of 355,034 recommendations. Panel A of Table 1 presents the breakdown of these recommendations by first and revised recommendations. A first recommendation refers to a new recommendation issued by an analyst on a stock for which there exists no previous recommendation in the past 12 months. This type of recommendation occurs either because the analyst has never issued a recommendation on this stock or because the most recent previous recommendation was issued more than 12 months earlier. A revised recommendation refers to a

3. http://mba.tuck.dartmouth.edu/pages/faculty/ken.french/

4. http://research.stlouisfed.org/fred2/

5. http://www.bus.emory.edu/AGoyal/ 
Table 1. Descriptive Statistics for Analyst Recommendations from I/B/E/S, 1994:01-2006:08. This table presents descriptive statistics for analyst recommendations for the period 1994:01-2006:08. Analyst recommendation data are from I/B/E/S. Our sample consists of all common stocks traded on NYSE/AMEX/Nasdaq with at least one analyst recommendation in I/B/E/S. Analyst rating score ranges from 1 to 5 . We categorize 5 as "strong buy", 4 as "buy", 3 as "hold", 2 as "underperform", and 1 as "sell". A revised recommendation refers to a new recommendation issued by an analyst on a stock for which there exists at least one previous recommendation in the past 12 months. A first recommendation refers to a new recommendation issued by an analyst on a stock for which there exists no previous recommendation in the past 12 months. Panel A presents the transition matrix for revised analyst recommendations. Panel B presents the descriptive statistics by year. The second column presents the number of firms with at least one valid recommendation in the I/B/E/S database during a particular year. The third and the fourth columns present the mean and median number of analyst issuing recommendations for each firm. The fifth and the sixth columns present the mean and median number of firms covered by each analyst. The seventh and the eighth columns present the number of unique brokers and analysts. The last column presents the average rating across all analyst recommendations in a year.

Panel A: Transition Matrix of Revised Analyst Recommendations

To Recommendation of:

\begin{tabular}{lrrrrrr}
\cline { 2 - 7 } From Recommendation of: & 1 & 2 & 3 & 4 & 5 & Total \\
\hline 1 & 307 & 175 & 2,843 & 276 & 331 & 3,932 \\
2 & 274 & 1,343 & 4,587 & 812 & 188 & 7,204 \\
3 & 2,892 & 5,221 & 11,941 & 21,307 & 14,488 & 55,849 \\
4 & 423 & 1,143 & 28,854 & 11,730 & 17,273 & 59,423 \\
5 & 515 & 374 & 18,946 & 17,189 & 7,090 & 44,114 \\
Subtotal & 4,411 & 8,256 & 67,171 & 51,314 & 39,370 & 170,522 \\
First recommendation & 2,646 & 4,964 & 62,693 & 62,726 & 51,483 & 184,512 \\
Total & 7,057 & 13,220 & 129,864 & 114,040 & 90,853 & 355,034 \\
\hline
\end{tabular}

Panel B: Descriptive Statistics by Year

\begin{tabular}{|c|c|c|c|c|c|c|c|c|}
\hline \multirow[b]{2}{*}{$\begin{array}{l}\text { Year } \\
(1)\end{array}$} & \multirow{2}{*}{$\begin{array}{r}\text { No. of } \\
\text { Firms } \\
(2)\end{array}$} & \multicolumn{2}{|c|}{ Analyst per firm } & \multicolumn{2}{|c|}{ Firm per analyst } & \multirow{2}{*}{$\begin{array}{r}\text { No. of } \\
\text { Brokers } \\
(7)\end{array}$} & \multirow{2}{*}{$\begin{array}{r}\text { No. of } \\
\text { Analysts } \\
(8)\end{array}$} & \multirow{2}{*}{$\begin{array}{r}\text { Average } \\
\text { Rating } \\
\text { (9) }\end{array}$} \\
\hline & & $\begin{array}{r}\text { Mean } \\
(3)\end{array}$ & $\begin{array}{r}\text { Median } \\
(4)\end{array}$ & $\begin{array}{r}\text { Mean } \\
(5)\end{array}$ & $\begin{array}{r}\text { Median } \\
(6)\end{array}$ & & & \\
\hline 1994 & 3,855 & 4.47 & 3 & 9.16 & 8 & 146 & 1,880 & 3.75 \\
\hline 1995 & 4,028 & 4.33 & 3 & 8.57 & 7 & 149 & 2,034 & 3.79 \\
\hline 1996 & 4,581 & 3.94 & 3 & 7.75 & 6 & 184 & 2,330 & 3.89 \\
\hline 1997 & 4,780 & 3.98 & 3 & 7.07 & 6 & 214 & 2,692 & 3.93 \\
\hline 1998 & 4,789 & 4.42 & 3 & 6.95 & 6 & 232 & 3,048 & 3.91 \\
\hline 1999 & 4,493 & 4.86 & 3 & 6.72 & 6 & 227 & 3,248 & 3.99 \\
\hline 2000 & 4,150 & 4.81 & 3 & 6.12 & 5 & 221 & 3,258 & 4.01 \\
\hline 2001 & 3,520 & 5.26 & 4 & 5.85 & 5 & 193 & 3,162 & 3.85 \\
\hline 2002 & 3,527 & 6.89 & 5 & 7.54 & 6 & 204 & 3,226 & 3.58 \\
\hline 2003 & 3,313 & 6.08 & 4 & 6.95 & 6 & 242 & 2,898 & 3.47 \\
\hline 2004 & 3,440 & 5.61 & 4 & 6.44 & 6 & 270 & 2,997 & 3.53 \\
\hline 2005 & 3,490 & 5.17 & 4 & 5.91 & 5 & 281 & 3,049 & 3.56 \\
\hline 2006 & 3,156 & 4.10 & 3 & 4.74 & 4 & 243 & 2,733 & 3.58 \\
\hline Average & 3,932 & 4.92 & 3 & 6.91 & 6 & 216 & 2,812 & 3.76 \\
\hline
\end{tabular}


new recommendation issued by an analyst on a stock for which there exists at least one previous recommendation in the past 12 months.

Of all recommendations, 184,512 are first recommendations that, by definition, cannot be classified as upgrades, downgrades, or reiterations. The remaining 170,522 are revised recommendations. Panel A also presents the $5 \times 5$ transition matrix for all revised analyst recommendations. The number in each cell shows the number of recommendations moved from the rating of the row index to the rating of the column index. Most of the recommendations are concentrated in the lower right $3 \times 3$ cells, consistent with an optimism bias in analyst recommendations.

Panel B of Table 1 provides descriptive statistics for our analyst recommendation sample for each year between 1994 and 2006. As shown in the first column, the number of sample firms ranges from 3,156 in 2006 to 4,789 in 1998. The average (median) number of analysts for each covered firm is 4.92 (3), while the mean (median) number of firms covered by each analyst is 6.91 (6). Columns (7) and (8) report the total number of brokerage firms and analysts for each year. There are on average 216 brokers and 2,812 analysts each year in our sample. These statistics are consistent with prior studies of analyst recommendations. The last column of Panel B shows the average analyst rating across all analysts and stocks for each year. Consistent with prior literature, we find that the average analyst rating is substantially greater than $3 \mathrm{ev-}$ ery year in our sample, indicating that analyst recommendations are on average positively biased. There appears to be a steady increase in optimism among the analysts from 1994 to 2000. However, the average analyst rating decreases significantly in 2001 and 2002, indicating that analysts issue less optimistic recommendations over this period. Since 2002, the average analyst rating has remained at a relatively stable level. The variation of analyst ratings over our sample period largely coincides with the cycles of the stock market. This finding is not surprising-prior literature (e.g., Jegadeesh, Kim, Krische, and Lee [2004)) documents a positive relation between analyst recommendations and past stock returns. The sharp decline of average analyst ratings during 2000-2002 is also partly due to the increasing media and regulatory attention, including the implementation of NASD Rule 2711 (discussed below).

\subsection{Measure Of Aggregate Analyst Recommendations}

We construct our aggregate analyst recommendation measure as the change in the average rating of all outstanding recommendations. ${ }^{6}$ We compute the aggregate analyst recommendation measure at both market (Chg_Avg_Rec) and industry (Ind_Chg_ Avg_Rec) levels. By averaging across all analyst recommendations, we eliminate the firm-specific information contained in these recommendations to focus on marketand industry-level information.

6. An outstanding recommendation refers to the most recent recommendation issued by an analyst on a stock during the past 12 months. Following Jegadeesh, Kim, and Krische, and Lee [2004], we impose this 12-month rule to eliminate stale recommendations. 
More specifically, in each month we first calculate the average analyst rating across all outstanding recommendations from all analysts for all stocks. We then define Chg_Avg_Rec as the monthly change in this average analyst rating for each month between 1994:01 and 2006:08:

$$
\text { Chg_Avg_Rec }{ }_{t}=\frac{1}{N_{t}}\left(\sum_{n=1}^{N_{t}} \text { Rating }_{n, t}\right)-\frac{1}{N_{t-1}}\left(\sum_{m=1}^{N_{t-1}} \text { Rating }_{m, t-1}\right) t=1, \ldots, 152
$$

where $N_{t}$ and $N_{t-1}$ denote the total number of outstanding recommendations across all analysts and stocks in month $t$ and $t-1$ respectively. ${ }^{7}$ We compute the industry level aggregate recommendation measure in a similar way as shown below:

$$
\text { Ind_Chg_Avg_Rec } c_{i, t}=\frac{1}{N_{i, t}}\left(\sum_{n=1}^{N_{i t}} \text { Rating }_{i, n, t}\right)-\frac{1}{N_{i, t-1}}\left(\sum_{m=1}^{N_{i t-1}} \text { Rating }_{i, m, t-1}\right) t=1, \ldots, 152
$$

where $N_{i, t}$ and $N_{i, t-1}$ denote the total number of outstanding recommendations across all analysts and stocks for industry $i$ in month $t$ and $t-1$ respectively.

In Figure 1, we plot the market-aggregated Chg_Avg_Rec for 1994-2006. There is substantial time-series variation in this variable during our sample period. We note that there is a downward spike in September 2002. This downward spike is attributable to the implementation of NASD Rule 2711 (Barber, Lehavy, McNichols, and Trueman [2006]). More specifically, NASD adopted Rule 2711 which requires a brokerage firm to define what each rating in its rating system means and requires that the "definition must be consistent with its plain meaning." The rule also requires each firm to disclose the percentage breakdown of all types of outstanding recommendations (buy/hold/sell). A similar rule, Rule 472, was adopted by the NYSE during the same time period. Barber, Lehavy, McNichols, and Trueman [2006] document the effects of NASD Rule 2711 on analyst recommendations. They show that the distribution of buy/hold/sell recommendations shifted significantly on September 9, 2002. Specifically, the percentage of buy (sell) recommendations increased (decreased) substantially on that day. To mitigate the effect of NASD Rule 2711 on our results, we eliminate those observations around the implementation of this rule from our regression analyses. ${ }^{8}$

7. An alternative way to construct the aggregate analyst recommendation measure is to average across all analyst recommendations for each firm first and then average across all firms. The main results of this paper are robust to this alternative aggregation scheme.

8. Our results are similar if we do not eliminate the observations associated with the implementation of NASD rule 2711. Moreover, we report in Section 3.1.5 that our results are unchanged if we focus only on the pre-NASD rule 2711 period. 


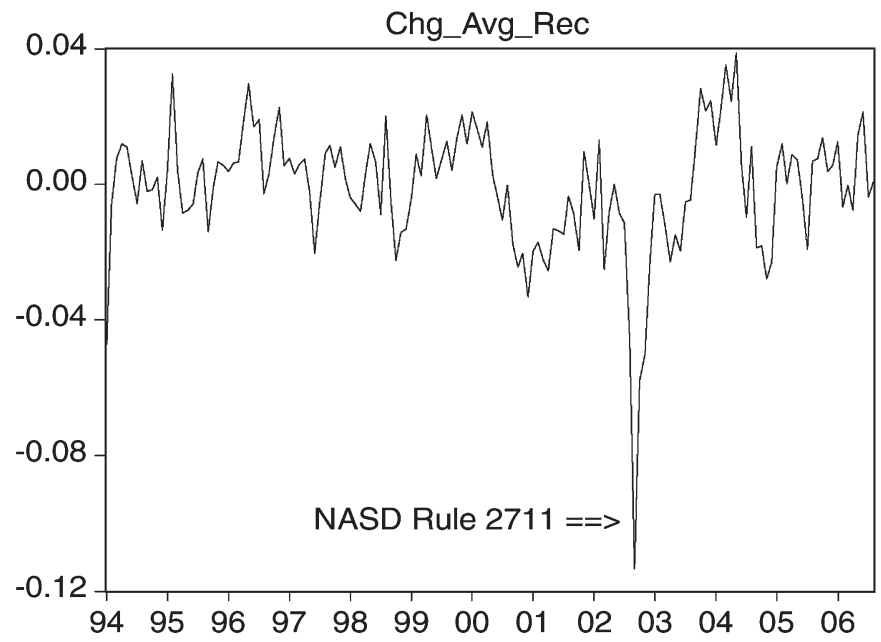

Figure 1. Changes in Aggregate Analyst Recommendations, 1994-2006. The sample period is from 1994:01 to 2006:08. Analyst recommendation data are from I/B/E/S. Our sample consists of all common stocks traded on NYSE/AMEX/Nasdaq with at least one analyst recommendation in I/B/ E/S. Analyst ratings range from 1 to 5 . We categorize 5 as "strong buy", 4 as "buy", 3 as "hold", 2 as "underperform", and 1 as "sell". Change in average analyst recommendation (Chg_Avg_Rec) is the difference between the current month's average analyst rating and the previous month's average analyst rating across all stocks. In September 2002, the NASD adopted Rule 2711, which requires brokerage firms to define what each rating in its rating system means and requires that the "definition must be consistent with its plain meaning." The rule also requires each firm to disclose the percentage breakdown of all types of outstanding recommendations (buy/hold/sell). A similar rule, Rule 472 , was adopted by the NYSE during the same time period.

\section{Do Aggregate Analyst Recommendations Predict Aggregate Returns?}

In this section, we examine whether aggregate analyst recommendations predict future aggregate returns. We first investigate the predictability of market returns in Section 3.1. We then examine the predictability of industry returns in Section 3.2.

\subsection{Market Returns}

3.1.1. Descriptive Statistics. Table 2 presents descriptive statistics for the change in aggregate analyst recommendations (Chg_Avg_Rec), market returns, and several macroeconomic variables for the period from January 1994 to August 2006. The monthly mean of Chg_Avg_Rec is -0.001 while the median is 0.002 , suggesting that on average analyst ratings have remained largely unchanged over our sample period. The average value-weighted CRSP index excess return is $0.6 \%$ per month, or approximately $7.2 \%$ per year. The monthly standard deviation of market excess returns is $4.295 \%$, or approximately $15 \%$ per year. Over our sample period, the average dividend yield, three-month T-bill rate, term spread, and default spread are $1.764 \%$, $3.841 \%, 2.078 \%$, and $2.109 \%$, respectively. 
Table 2. Descriptive Statistics for Changes in Aggregate Analyst Recommendations, Market Excess Returns, and Other Predictive Variables. This table presents the descriptive statistics for aggregate analyst recommendations, market excess returns, and macroeconomic variables. The sample period is from 1994:01 to 2006:08. All variables are monthly. Analyst recommendation data are from I/B/E/S. Change in average analyst recommendation (Chg_Avg_Rec) is the difference between the current month's average analyst rating and the previous month's average analyst rating across all stocks. EXRET is the CRSP value-weighted market excess return. Dividend yield (DP) is the dividend yield of the S\&P500 index. TB3M is the 3-month Treasury bill rate. Term spread (TERM) is the term premium calculated as the difference between long-term government bond yield and 3-month T-bill rates. Default spread (DEF) is the default yield calculated as the difference between Moody's Baa corporate bond yield and 10-year T-bond yield. In Panel B, we report Pearson correlations. The superscripts ***, **, and * denote statistical significance at the 1,5 , and 10 percent levels.

Panel A: Univariate Statistics

\begin{tabular}{lccccc} 
& Mean & Median & $\begin{array}{c}\text { Standard } \\
\text { Deviation }\end{array}$ & Maximum & Minimum \\
\hline $\begin{array}{l}\text { Change in average analyst } \\
\quad \text { recommendation (Chg_Avg_Rec) }\end{array}$ & -0.001 & 0.002 & 0.019 & 0.039 & -0.113 \\
$\begin{array}{l}\text { Value-weighted market excess } \\
\quad \text { return (EXRET) - \% }\end{array}$ & 0.600 & 1.270 & 4.295 & 8.180 & -16.200 \\
$\begin{array}{l}\text { Dividend yield (DP) - \% } \\
\text { Three-month T-bill rate (TB3M) - \% }\end{array}$ & 1.764 & 1.686 & 0.472 & 2.903 & 1.077 \\
$\begin{array}{l}\text { Term spread (TERM) - \% } \\
\text { Default spread (DEF) - \% }\end{array}$ & 2.078 & 1.825 & 1.288 & 4.520 & -0.410 \\
\hline
\end{tabular}

Panel B: Correlation Matrix

\begin{tabular}{lllllll} 
& Chg_Avg_Rec & EXRET & DP & TB3M & TERM & DEF \\
\hline Chg_Avg_Rec & 1 & & & & & \\
EXRET & 0.02 & 1 & & & \\
DP & 0.05 & 0.00 & 1 & & \\
TB3M & $0.17^{* *}$ & 0.01 & 0.12 & 1 & \\
TERM & -0.06 & 0.01 & $0.23^{* * *}$ & $-0.82^{* * *}$ & 1 & \\
DEF & $-0.50^{* * *}$ & -0.12 & $-0.50^{* * *}$ & $-0.57^{* * *}$ & $0.36^{* * *}$ & 1 \\
\hline
\end{tabular}

Panel B of Table 2 presents the Pearson correlations among the aggregate analyst recommendation and the above macroeconomic variables. Chg_Avg_Rec has low correlations with the macroeconomic variables, with the exception of three-month T-bill rate and default spread. Chg_Avg_Rec is significantly negatively correlated with default spread (-0.5) and positively correlated with the three-month T-bill rate (0.17). A significant negative correlation exists between dividend yield and default spread $(-0.5)$ over our sample period. There is also a significant negative correlation $(-0.82)$ between the term spread and the 3-month Treasury bill rate.

3.1.2. Regression Model and Methods. To examine whether changes in aggregate analyst recommendations forecast future market returns, we estimate the following 
Table 3. Regression of One-quarter-ahead Market Excess Returns on Changes in Aggregate Analyst Recommendations. This table reports the results for regressions of one-quarter-ahead market excess returns on changes in aggregate analyst recommendations. The sample period is from 1994:01 to 2006:08. We exclude the observations around the implementation of NASD Rule 2711. All variables are monthly. Analyst recommendation data are from I/B/E/S. The dependent variable is one-quarter-ahead market excess returns from CRSP. Chg_Avg_Rec is the difference between the current month's average analyst rating and the previous month's average analyst rating across all stocks. The lagged one-quarter average Chg_Avg_Rec is the average Chg_Avg_Rec over the past three months. Numbers in parentheses are Newey-West adjusted p-values. The superscripts *** , **, and * denote statistical significance at the 1,5 , and 10 percent levels.

Dependent Variable:

One-quarter-ahead Market Excess Return

(1)

\begin{tabular}{lcc}
\hline Intercept & $0.020^{* *}$ & $0.022^{* *}$ \\
Lagged one-quarter average Chg_Avg_Rec & $(0.030)$ & $(0.040)$ \\
& $1.005^{* * *}$ & $1.025^{* * *}$ \\
Lagged one-quarter market excess return & $(0.003)$ & $(0.003)$ \\
$R^{2}$ & & -0.078 \\
\end{tabular}

time-series regression:

$\operatorname{EXRET}_{t, t+3}=\alpha_{0}+\alpha_{1}$ Chg_Avg_Rec $\operatorname{Rec}_{t-3, t}+\alpha_{2} \operatorname{EXRET}_{t-3, t}+e_{t}$

where EXRETt, $t+3$ is the one-quarter-ahead market excess return, Chg_Avg_Rec ${ }_{t-3, t}$ is the average Chg_Avg_Rec over the past three months, and $E X R E T_{t-3, t}$ is the lagged one-quarter market excess returns. We control for the lagged market excess return to capture possible autocorrelation in market excess returns. We follow Jegadeesh, Kim, Krische, and Lee [2004] and conduct our analysis at the quarterly horizon.

To increase statistical power, we follow many papers in the empirical asset pricing literature (e.g., Fama and French [1988] and Lakonishok and Lee [2001]) to use overlapping monthly observations in our regressions. This approach implies that the regression residuals will be serially correlated. In addition, the regression residuals might be conditionally heteroskedastic. To correct for serial correlation and conditional heteroskedasticity, we use Newey-West [1987] standard errors. ${ }^{9,10}$

3.1.3. Baseline Regression Results. Table 3 reports the estimation results for regression equation (3). We find evidence that changes in aggregate analyst recommendations predict market excess returns one quarter ahead. The coefficient on

9. The number of lags is chosen optimally based on a suggestion by Newey and West [1987].

10. As a robustness check, we also use Hodrick [1992] standard errors, which are designed to correct for serial correlation due to overlapping observations. See Section 3.1.5 for more details. 
Chg_Avg_Rec $\operatorname{Rt}_{t, 3, t}$ is positive and statistically significant at the 1 percent level based on Newey-West standard errors. The predictive ability of changes in aggregate analyst recommendations is unchanged after controlling for lagged market excess returns.

Our results are economically meaningful. A one-standard deviation increase in Chg_Avg_Rec t-3,t $_{\text {is }}$ is associated with an increase in the next quarter's market excess return of approximately $1.7 \%$. The R-squares of these predictive regressions are $4.6 \%$ to $5.5 \%$, a level similar to or higher than those of other well-documented predictors of market returns for quarterly horizons (e.g., Fama and French [1988, 1989] and Lamont [1998]).

3.1.4. Controlling for Macroeconomic Variables. There is considerable evidence that market expected returns are time-varying and predictable. Previous literature (e.g., Fama and Schwert [1977], Keim and Stambaugh [1986], Campbell [1987], and Fama and French $[1988,1989])$ shows that macroeconomic variables such as dividend yield, the three-month T-bill rate, the term spread, and the default spread predict future market excess returns. To test if the predictive ability of aggregate analyst recommendations is subsumed by macroeconomic variables that have been shown to influence market returns, we estimate the following regression:

$$
\text { EXRET }_{t, t+3}=\beta_{0}+\beta_{1} C h g_{-} A v g_{-} \operatorname{Rec}_{t-3, t}+\beta_{2} D P_{t}+\beta_{3} T B 3 M_{t}+\beta_{4} T E R M_{t}+\beta_{5} D E F_{t}+e_{t}
$$

where DP, TB3M, TERM, and DEF are the dividend yield, the three-month T-bill rate, the term spread, and the default spread, respectively. ${ }^{11}$

Table 4 presents the regression results. We first control for the four macroeconomic variables one at a time and then all together in the last regression. The coefficients on Chg_Avg_Rec $\operatorname{Re}_{t-3, t}$ are positive and statistically significant at the one percent level in all regressions. The coefficient on $C_{g}{ }_{-} A v g_{-} \operatorname{Rec}_{t-3, t}$ remains significant when we control for all four macroeconomic variables simultaneously. ${ }^{12}$

Overall, we document that changes in aggregate analyst recommendations continue to predict future market excess returns after controlling for dividend yield, the short-term interest rate, the term spread, and the default spread in the predictive regressions. The results suggest that analyst recommendations contain market-level information that is incremental to that contained in the macroeconomic predictive variables.

11. We do not control for lagged market excess returns in this regression because the results in Table 3 suggest that lagged market excess return neither correlates with future market excess return nor affects the predictive ability of aggregate analyst recommendations. Controlling for lagged market excess return in regression equation (4) does not affect our results.

12. The result that three of the four macroeconomic variables do not predict market returns is consistent with Goyal and Welch [2008], who find that these variables are not reliable predictors of market excess returns since the oil crisis of the early 1970s. 
Table 4 . Regression of One-quarter-ahead Market Excess Returns on Changes in Aggregate Analyst Recommendations, Controlling for Macroeconomic Variables. This table reports the results for regressions of one-quarter-ahead market excess returns on changes in aggregate analyst recommendations controlling for macroeconomic variables. The sample period is from 1994:01 to 2006:08. We exclude the observations around the implementation of NASD Rule 2711. All variables are monthly. Analyst recommendation data are from I/B/E/S. The dependent variable is one- quarter-ahead market excess returns from CRSP. The aggregate analyst recommendation measure is the lagged one-quarter average of Chg_Avg_Rec. Chg_Avg_Rec is the difference between the current month's average rating and the previous month's average rating across all stocks. Dividend yield (DP) is the dividend yield of the S\&P500 index. TB3M is the 3-month Treasury bill rate. Term spread (TERM) is the term premium calculated as the difference between long-term government bond yield and 3-month T-bill rates. Default spread (DEF) is the default yield calculated as the difference between Moody's Baa corporate bond yield and 10-year T-bond yield. Numbers in parentheses are Newey-West adjusted $p$-values. The superscripts ${ }^{* * *},{ }^{* *}$, and * denote statistical significance at the 1, 5, and 10 percent levels.

\begin{tabular}{lccccccc}
\hline Model & Intercept & $\begin{array}{c}\text { Lagged } \\
\text { 1-qtr average } \\
\text { Chg_Avg_Rec }\end{array}$ & $\begin{array}{c}\text { Dividend } \\
\text { yield }\end{array}$ & $\begin{array}{c}\text { 3-month } \\
\text { T-bill rate }\end{array}$ & $\begin{array}{c}\text { Term } \\
\text { spread }\end{array}$ & $\begin{array}{c}\text { Default } \\
\text { spread }\end{array}$ & $R^{2}$ \\
\hline$(1)$ & -0.054 & $1.046^{* * *}$ & $4.193^{* *}$ & & & & 0.123 \\
& $(0.109)$ & $(0.001)$ & $(0.016)$ & & & \\
$(2)$ & 0.024 & $1.019^{* * *}$ & & -0.095 & & & 0.055 \\
& $(0.424)$ & $(0.004)$ & & $(0.892)$ & & & 0.055 \\
$(3)$ & 0.018 & $1.013^{* * *}$ & & & 0.113 & & \\
& $(0.367)$ & $(0.003)$ & & & $(0.900)$ & -1.510 & 0.066 \\
$(4)$ & 0.051 & $0.818^{* * *}$ & & & & $(0.438)$ & \\
& $(0.160)$ & $(0.003)$ & & & & & \\
$(5)$ & -0.034 & $1.397^{* * *}$ & $7.926^{* * *}$ & -1.815 & -2.680 & 1.945 & 0.169 \\
& $(0.685)$ & $(0.001)$ & $(0.008)$ & $(0.103)$ & $(0.104)$ & $(0.460)$ & \\
\hline
\end{tabular}

3.1.5. Robustness Tests. In this section, we discuss the results of several robustness tests. Due to space constraints, these results are not reported in the paper but are available upon request.

Evidence Prior to NASD Rule 2711. The implementation of NASD Rule 2711 on September 9, 2002 results in a large negative observation for changes in aggregate analyst recommendations. We eliminated this observation from our previous regression analyses. A more conservative approach to mitigating the effect of NASD Rule 2711 is to use only the pre-NASD Rule 2711 period. We stress that this approach is conservative in that the decline in analyst ratings in the latter half of 2002 might be driven by factors other than the NASD Rule 2711. Barber et al. [2006] admit that the decrease in buy recommendations in 2002 "probably was due, in part, to a worsening economy and a declining stock market." By excluding this period, we discard potentially useful data. Despite the shorter sample period, our main finding that aggregate analyst recommendations are positively related to future market returns continues to hold.

Hodrick [1992] Standard Errors. To account for potential serial correlation in regression residuals caused by overlapping data, we use a procedure developed by 
Hodrick [1992] to estimate standard errors. ${ }^{13}$ Although Hodrick standard errors are slightly larger than Newey-West standard errors, we continue to find that changes in aggregate analyst recommendations are significantly related to future market returns.

Stambaugh Bias. Stambaugh $[1986,1999]$ shows that when stock returns are regressed on lagged stochastic regressors that are persistent, the OLS estimates may be substantially biased in small samples. We follow Stambaugh [1999] and Baker, Taliaferro, and Wurgler [2006] to evaluate the magnitude of the small-sample bias in our predictive regressions. We find that this bias is negligible in our setting, accounting for less than $1 \%$ of the coefficient estimate, suggesting that our inferences regarding the predictive ability of changes in aggregate analyst recommendations are unaffected by small-sample bias.

Excluding the First Observation. The first observation of our aggregate analyst recommendation measure is substantially negative. To test if our predictive results are unduly influenced by this observation, we reestimate regression equations (3) and (4) while excluding the first observation. We find that our results are robust to this exclusion.

Controlling for Forecasted Earnings Yield and Analysts' Forecast Dispersion. Lander, Orphanides, and Douvogiannis [1997] investigate a security valuation theory that presumes a simple relationship between the earnings yield and the Treasury bond yield. The basic idea is that investors are constantly making a choice between stocks and bonds. Therefore, the relative magnitude of the forecasted earnings yield and Treasury bond yields is informative about the relative valuation of stocks and bonds. Lander, Orphanides, and Douvogiannis find evidence consistent with this hypothesis. Our paper is different from Lander, Orphanides, and Douvogiannis in two aspects. First, we examine analyst recommendations as opposed to analyst earnings forecasts. Second, Lander, Orphanides, and Douvogiannis focus on the relative magnitude of earnings yield and bond yield, and do not investigate the information content of analysts' forecast per se. In another related paper, Park [2005] finds that analyst earnings forecast dispersion predicts future aggregate stock returns. To show that our findings are distinct from these two papers, we control for the difference between forecasted earnings yield and Treasury bond yield as well as analyst earnings forecast dispersion in our predictive regressions. We find that controlling for these variables does not change our results.

\subsection{Industry Returns}

In Section 3.1, we demonstrate that market-aggregated analyst recommendations predict future market returns. In this section, we examine the predictive content of industry-aggregated analyst recommendations. This analysis is natural because an-

13. Using a Monte-Carlo analysis, Ang and Bekaert [2007] find that Hodrick standard errors possess excellent finite sample properties. 
Table 5. Regression of One-quarter-ahead Industry Portfolio Returns on Changes in IndustryAggregated Analyst Recommendations. This table reports the results for regressions of one-quarter-ahead industry excess returns on industry- aggregated changes in analyst recommendations. Our sample consists of all common stocks traded on NYSE/AMEX/Nasdaq with at least one analyst recommendation in I/B/E/S. The sample period is from 1994:01 to 2006:08. We exclude the observations around the implementation of NASD Rule 2711. All variables are monthly. Industry classifications are based on the 48 industry groups of Fama and French [1997]. The dependent variable is one-quarter-ahead Fama-French Industry portfolio excess returns (IND_RET). The industry-aggregated analyst recommendation measure is the lagged one-quarter average of Ind_Chg_Avg _ Rec. Ind_Chg_Avg_Rec is the difference between the current month's average rating and the previous month's average rating across all stocks in an industry. Panel A shows the pooled regression results with industry fixed effects. Statistical significance is based on industry clustered standard errors. Panel B reports the results of the Fama-MacBeth [1973] type of regressions. Numbers in parentheses are p-values. The superscripts ***,**, and * denote statistical significance at the 1,5 , and 10 percent levels.

Panel A: Pooled Regressions

\begin{tabular}{lcccc} 
Model & Intercept & $\begin{array}{c}\text { Lagged one-quarter } \\
\text { average Ind_Chg_Avg_Rec }\end{array}$ & $\begin{array}{c}\text { Lagged one-quarter } \\
\text { IND_RET }\end{array}$ & $R^{2}$ \\
\hline$(1)$ & -0.000 & $0.100^{*}$ & & 0.014 \\
& $(0.784)$ & $(0.069)$ & $-0.076^{* * *}$ & 0.020 \\
$(2)$ & 0.000 & $0.105^{*}$ & $(0.001)$ & \\
\hline
\end{tabular}

Panel B: Fama-MacBeth Regressions

\begin{tabular}{lcccc} 
Model & Intercept & $\begin{array}{c}\text { Lagged one-quarter } \\
\text { average Ind_Chg_Avg_Rec }\end{array}$ & $\begin{array}{c}\text { Lagged one-quarter } \\
\text { IND_RET }\end{array}$ & $R^{2}$ \\
\hline$(1)$ & $0.021^{* * *}$ & $0.158^{* * *}$ & & 0.015 \\
& $(0.000)$ & $(0.010)$ & $-0.100^{* * *}$ & 0.035 \\
$(2)$ & $0.023^{* * *}$ & $0.150^{* *}$ & $(0.001)$ & \\
\hline
\end{tabular}

alysts typically specialize by industry (Boni and Womack [2006]). If analysts use industry-level information in making stock recommendations, we would expect industry-aggregated analyst recommendation to predict industry returns. Similar to our analysis of market returns, we estimate the following predictive regression:

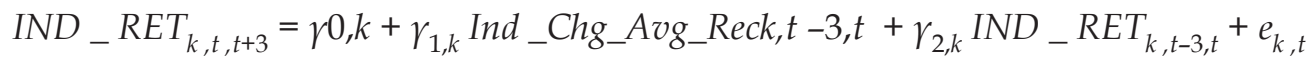

where IND_RET $T_{k, t, t+3}$ and IND_RET $T_{k, t-3, t}$ are one-quarter-ahead and lagged one-quarter excess returns on the kth Fama-French industry portfolio. We estimate regression equation (5) using both pooled OLS and Fama-MacBeth [1973] methods. For pooled regressions, we include industry fixed effects and estimate industry-clustered standard errors. In the Fama-MacBeth approach, we estimate equation (5) industry by industry and report the average regression coefficients and their associated $p$-values.

Panel A of Table 5 presents the results based on pooled regressions, while Panel $B$ presents that Fama-MacBeth results. In Panel A, we find evidence that industry-ag- 
gregated analyst recommendations weakly predict future industry returns. The coefficient on the lagged industry-aggregated analyst recommendations is positive and significant at the 10 percent level. ${ }^{14}$ That is, an increase (decrease) in average analyst rating for stocks in a given industry tends to be followed by a relatively high (low) return for this industry. Controlling for lagged industry return does not change this result. Panel B shows the results for the Fama-MacBeth approach. The coefficients on lagged industry-aggregated analyst recommendations are positive and statistically significant at the 1 (5) percent level before (after) controlling for lagged industry returns. Overall, we find modest evidence that industry-aggregated analyst recommendations have predictive power for future industry returns. This finding is consistent with our previous result on market returns, and is also consistent with Piotroski and Roulstone [2004] who find that analysts increase the amount of industry-level information in stock prices.

Boni and Womack [2006] also analyze the predictive ability of industry-aggregated analyst recommendations, but they focus on whether industry-aggregated analyst recommendations help forecast the cross-section of industry returns. In particular, they test whether industries experiencing more favorable changes in average analyst ratings outperform industries experiencing less favorable changes in average analyst ratings. In contrast, we examine the time-series predictive ability of industryaggregated analyst recommendations for a given industry. Put differently, Boni and Womack focus on relative performance across industries whereas we focus on performance within each industry over time.

\section{Do Aggregate Analyst Recommendations Predict Aggregate Earnings Growth?}

In the previous section, we provide evidence that changes in aggregate analyst recommendations forecast future aggregate returns. In this section we examine whether changes in aggregate analyst recommendations also forecast future aggregate earnings. Campbell [1991] and Vuolteenaho [2002] show that unexpected stock returns can be decomposed into two components: (1) changes in expectations about future cash flows (cash-flow news); and (2) changes in expectations about future discount rates (expected-return news). To provide insight into the channel through which analyst recommendations predict aggregate returns, we examine whether changes in aggregate analyst recommendations predict future aggregate earnings growth. ${ }^{15}$

14. We also estimate two-way clustered standard errors (Gow, Ormazabal, and Taylor [2008] and Petersen [2008]) in order to account for time-series and cross-sectional dependence simultaneously. We find that the coefficients on lagged industry-aggregated analyst recommendations are all positive, but the $\mathrm{p}$-values range from 16 to $18 \%$.

15. We recognize that the cash-flow news and the expected-return news may be correlated or jointly determined, which makes it difficult to cleanly separate these two components of asset returns. 


\subsection{Data And Measures}

To construct aggregate earnings growth measures, we obtain accounting data from COMPUSTAT quarterly files for our sample period. For each firm-quarter observation we calculate the seasonally differenced quarterly earnings (dE), which is computed as the income before extraordinary items in million dollars (Item \#8) minus its value four quarters previously. To ensure that fiscal quarters are aligned, we follow Kothari, Lewellen, and Warner [2006] and keep only firms that have March, June, September and December fiscal year end. We also require that each firm-quarter observation have non-missing values for the inputs for the aggregate earnings change measures discussed below. We follow Kothari, Lewellen, and Warner [2006] to construct five measures of aggregate earnings growth.

Our first aggregate earnings measure, $\mathrm{d} E / \mathrm{P}$-agg, is computed as the cross-sectional sum of $\mathrm{dE}$ scaled by the cross-sectional sum of market capitalization four quartersago $\left(M C A P_{q-4}\right)$. MCAP is measured as share price (Item \#14) times shares outstanding (Item \#61).

$$
\mathrm{d} E / P-a g g_{q}=\frac{\sum_{i=1}^{N_{q}} \mathrm{~d} E_{i, q}}{\sum_{i=1}^{N_{q}} M C A P_{i, q-4}}
$$

where $N_{q}$ is the number of sample firms in quarter $q$.

Our second measure, $\mathrm{d} E / B E-a g g$, is computed as the cross-sectional sum of $\mathrm{d} E$ scaled by the cross-sectional sum of book value of equity four quarters ago $\left(B E_{q-4}\right)$. $B E$ is measured as Item \#60.

$$
\mathrm{d} E / B E-\operatorname{agg}_{q}=\frac{\sum_{i=1}^{N_{q}} \mathrm{~d} E_{i, q}}{\sum_{i=1}^{N_{q}} B E_{i, q-4}} .
$$

Our third measure, $\mathrm{d} E / E$-agg, is computed as the cross-sectional sum of $\mathrm{dE}$ scaled by the cross-sectional sum of earnings four quarters ago $\left(E_{q-4}\right)$. E is measured as Item \#8.

$$
\mathrm{d} E / E-a g g_{q}=\frac{\sum_{i=1}^{N_{q}} \mathrm{~d} E_{i, q}}{\sum_{i=1}^{N_{q}} E_{i, q-4}} .
$$

Our fourth and fifth measures, $\mathrm{d} E / P-v w$ and $\mathrm{dE} / \mathrm{P}-\mathrm{ew}$, are the value-weighted (based on market capitalization) and equal-weighted averages of per share measures of $\mathrm{d} E$ 
scaled by per share stock price four quarters ago $\left(P_{q-4}\right) \cdot{ }^{16}$ Following Kothari, Lewellen, and Warner [2006], we exclude firms with stock price less than $\$ 1$ and trim the sample at $0.5 \%$ on both tails based on $\mathrm{d} E / P$. The fourth and fifth measures are thus:

$$
\begin{aligned}
& \mathrm{d} E / P-v w_{q}=\sum_{i=1}^{N_{q}} \omega_{i, q}\left(\frac{\mathrm{d} E_{q}}{P_{q-4}}\right)_{i} \text { where } \omega_{i, q}=\frac{M C A P_{i, q-4}}{\sum_{i=1}^{N_{q}} M C A P_{i, q-4}}, \\
& \mathrm{~d} E / P-e w_{q}=\sum_{i=1}^{N_{q}} \omega_{i, q}\left(\frac{\mathrm{d} E_{q}}{P_{q-4}}\right)_{i} \quad \text { where } \omega_{i, q}=\frac{1}{N_{q}},
\end{aligned}
$$

where $N_{q}$ is the number of firms with available data contributing to the metric in quarter $q$. In addition to the market level measures, we also construct five measures of industry-aggregated earnings changes based on equations (6) through (10) for each Fama-French industry.

Kothari, Lewellen, and Warner [2006] construct all of the above five measures but only use three of them ( $\mathrm{d} E / B E-a g g, \mathrm{~d} E / P-v w$, and $\mathrm{d} E / P-e w)$ in their main analyses. We use all five measures to ensure that our results are not driven by any particular measure.

\subsection{Predictability Of Aggregate Earnings}

To examine whether changes in aggregate analyst recommendations forecast aggregate earnings, we estimate the following quarterly time-series regression:

$$
\mathrm{d} E / S_{q+1}=a_{0}+a_{1} \text { Chg_Avg_Rec } \operatorname{Rec}_{q}+e_{q+1}
$$

where $\mathrm{d} E / S_{q+1}$ is the one-quarter-ahead aggregate earnings growth and is measured as $\mathrm{d} E / P$-agg, $\mathrm{d} E / B E$-agg, $\mathrm{d} E / E-a g g, \mathrm{~d} E / P-v w$, or $\mathrm{d} E / P$-ew. Chg_Avg_Rec $c_{\mathrm{q}}$ is the average Chg_Avg_Rec over the current quarter. To account for possible serial correlation in regression residuals, we conduct our inferences using Newey-West standard errors.

4.2.1. Market Level Results. We first estimate regression (11) at the market level. Table 6 presents the results. We find modest evidence that changes in aggregate analyst recommendations predict future aggregate earnings growth. Specifically, the coefficient estimates (a1) are positive for all five specifications. This result suggests that an increase in average analyst ratings tends to be followed by an increase in aggregate earnings. The coefficient is statistically significant at the 10 percent level for the first four regressions ( $p$-values range from 0.058 to 0.087 ). In the last regression where the dependent variable is $\mathrm{d} E / P$-ew , the coefficient estimate is insignificant $(p$-value $=$ 0.188). One potential reason for the weak result for $\mathrm{d} E / P$-ew is that small firms have

16. We adjust $\mathrm{d} E$ to account for stock split/dividends so that the adjusted-dE is comparable to per share price four quarters ago $\left(P_{q-4}\right)$. 
Table 6. Regression of One-quarter-ahead Aggregate Earnings on Changes in Aggregate Analyst Recommendations. This table reports the results for regressions of one-quarter-ahead aggregate earnings growth on changes in aggregate analyst recommendations. The sample period is from 1994:Q1 to 2006:Q3. We exclude the observations around the implementation of NASD Rule 2711. All variables are quarterly. Earnings and analyst recommendation data are from COMPUSTAT and $\mathrm{I} / \mathrm{B} / \mathrm{E} / \mathrm{S}$ respectively. The dependent variable is one-quarter-ahead aggregate earnings changes. Aggregate earning changes are measured as dE/P-agg, dE/BE-agg, dE/E-agg, dE/P-vw, and $\mathrm{dE} / \mathrm{P}-\mathrm{ew} . \mathrm{dE}$ is the aggregate seasonally differenced earnings. Pagg and BE-agg are the aggregate market and book values of equity four quarters ago. E-agg is the aggregate earnings four quarters ago. $\mathrm{dE} / \mathrm{P}-\mathrm{vw}(\mathrm{dE} / \mathrm{P}-\mathrm{ew})$ is the value-weighted (equal-weighed) averages of firm-level $\mathrm{dE} / \mathrm{P}$ ratio. The aggregate analyst recommendation measure is the lagged one-quarter average of Chg_Avg Rec. Chg_Avg_Rec is the difference between the current month's average rating and the previous month's average rating across all stocks. Numbers in parentheses are Newey-West adjusted p-values. The superscripts ***,**, and * denote statistical significance at the 1,5 , and 10 percent levels.

\begin{tabular}{lcccc}
\hline Model & $\begin{array}{c}\text { Aggregate Earnings } \\
\text { Growth Measure }\end{array}$ & Intercept & $\begin{array}{c}\text { Lagged one-quarter } \\
\text { average Chg_Avg_Rec }\end{array}$ & $R^{2}$ \\
\hline$(1)$ & dE/P-agg & 0.001 & $0.120^{*}$ & 0.161 \\
& $(0.109)$ & $(0.058)$ & & $0.368^{*}$ \\
$(2)$ & dE/BE-agg & 0.003 & & 0.182 \\
& $(0.294)$ & $(0.071)$ & $16.387^{*}$ & 0.101 \\
$(3)$ & dE/E-agg & 0.174 & $0.106^{*}$ & 0.138 \\
& $(0.176)$ & $(0.087)$ & & 0.059 \\
$(4)$ & dE/P-vw & $0.001^{*}$ & 0.086 & \\
& $(0.098)$ & $(0.063)$ & & \\
\hline
\end{tabular}

a disproportional impact on $\mathrm{d} E / P$-ew. To the extent that earnings of small firms are more volatile and more idiosyncratic, their growth may be less predictable by aggregate analyst recommendations.

4.2.2. Industry Level Results. We next examine the predictive ability of aggregate analyst recommendations for industry-aggregated earnings. More specifically, we estimate the following quarterly time-series regression at the industry level:

$$
\text { Ind_ } \mathrm{d} E / S_{k, q+1}=\beta_{0}+\beta_{1} \text { Ind_Chg_Avg_Rec }{ }_{k, q}+e_{k, q+1}
$$

where Ind_dE/S ${ }_{k, q+1}$ is the one-quarter-ahead industry-aggregated earnings change for the $k$ th Fama-French industry portfolio. Ind_d $\mathrm{d} / S_{k, q+1}$ is measured as $\mathrm{d} E / P$-agg, $\mathrm{d} E / B E-a g g, \mathrm{~d} E / E-a g g, \mathrm{~d} E / P-v w$, or $\mathrm{d} E / P$-ew computed for the $k$ th Fama-French industry. Ind_Chg_Avg_Rec ${ }_{k, q}$ is the average Chg_Avg_Rec over the current quarter for the $k$ th Fama-French industry. Similar to our return analysis, we estimate the above regression equation using both pooled OLS and Fama- MacBeth methods. ${ }^{17}$

17. Similar to our predictive regressions of industry returns, we implement industry fixed effects in the pooled OLS regressions and evaluate statistical significance based on industry-clustered standard errors. 
Table 7. Regression of One-quarter-ahead Industry Aggregated Earnings on Changes in Industry Aggregated Analyst Recommendations. This table reports the results for regressions of one-quarter-ahead industry-aggregated earnings growth on industry-aggregated changes in analyst recommendations. The sample period is from 1994:Q1 to 2006:Q3. We exclude the observations around the implementation of NASD Rule 2711. All variables are quarterly. Earnings and analyst recommendation data are from COMPUSTAT and I/B/E/S respectively. Industry classifications are based on the 48 industry groups of Fama and French [1997]. The dependent variable is one-quarter-ahead industry aggregate earnings changes. Industry aggregate earning changes are measured as $\mathrm{dE} / \mathrm{P}$-agg, $\mathrm{dE} / \mathrm{BE}-\mathrm{agg}, \mathrm{dE} / \mathrm{E}-\mathrm{agg}, \mathrm{dE} / \mathrm{P}-\mathrm{vw}$, and $\mathrm{dE} / \mathrm{P}$-ew. $\mathrm{dE}$ is the aggregate seasonally differenced earnings computed for each industry. P-agg and BE-agg are the industry level aggregate market and book values of equity four quarters ago. E-agg is the industry level aggregate earnings four quarters ago. dE/P-vw (dE/P-ew) is the value-weighted (equal-weighed) averages of firmlevel $\mathrm{dE} / \mathrm{P}$ ratios across stocks for each industry. The industry-aggregated analyst recommendation measure is the lagged one-quarter average of Ind_Chg_Avg_Rec. Ind_Chg_Avg_Rec is the difference between the current month's average rating and the previous month's average rating across all stocks in an industry. Panel A shows the pooled regression results with industry fixed effects. Statistical significance is based on industry clustered standard errors. Panel B reports the results of the Fama-MacBeth [1973] type of regressions. Numbers in parentheses are p-values. The superscripts $* * *, * *$, and * denote statistical significance at the 1,5 , and 10 percent levels.

Panel A: Pooled Regressions

\begin{tabular}{lcccc} 
Model & $\begin{array}{c}\text { Industry-aggregated } \\
\text { Earnings Growth } \\
\text { Measure }\end{array}$ & Intercept & $\begin{array}{c}\text { Lagged } \\
\text { 1-qtr average } \\
\text { Ind_Chg_Avg_Rec }\end{array}$ & $R^{2}$ \\
\hline$(1)$ & dE/P-agg & $0.001^{* * *}$ & $0.047^{* * *}$ & 0.040 \\
$(2)$ & dE/BE-agg & $0.001)$ & $(0.001)$ & 0.036 \\
& dE/E-agg & $(0.001)$ & $0.106^{* * *}$ & 0.021 \\
$(3)$ & $-0.004^{* *}$ & $(0.001)$ & 0.035 \\
$(4)$ & dE/P-vw & $0.017)$ & $\left(0.0355^{* *}\right.$ & 0.032 \\
$(5)$ & dE/P-ew & $\left(0.001^{* * *}\right.$ & $0.043^{* * *}$ & \\
& & $0.005^{* * *}$ & $(0.001)$ & $0.043^{* *}$ \\
\hline
\end{tabular}

Panel B: Fama-MacBeth Regressions

Industry-aggregated Earnings Growth

Model Measure

Lagged

1-qtr average

(1)

(2)

dE/P-agg $0.001^{\text {** }}$

$(0.021)$

$0.002^{* * *}$

(0.001)

(3)

dE/BE-agg

$0.169^{* * *}$

(0.001)

(4)

dE/E-agg

$0.001^{* *}$

$(0.017)$

(5)

dE/P-vw

$0.003^{* * *}$

dE/P-ew

(0.001) Ind_Chg_Avg_Rec

$R^{2}$

$\begin{array}{ll}0.055^{* * *} & 0.055 \\ (0.001) & \\ 0.156^{* * *} & 0.054 \\ (0.001) & \\ 1.886^{* *} & 0.033 \\ (0.035) & \\ 0.051^{* * *} & 0.054 \\ (0.001) & \\ 0.066^{* * *} & 0.057 \\ (0.001) & \end{array}$


Panel A of Table 7 presents the pooled regression results. Regardless of the aggregate earnings measure, we find a positive and significant relation between past industry-aggregated recommendations and future industry-aggregated earnings. The results are statistically significant at the 1 percent level for $\mathrm{d} E / P$-agg, $\mathrm{d} E / \mathrm{BE}$-agg, and $\mathrm{d} E / P-v w$, and at the 5 percent level for $\mathrm{d} E / E$-agg and $\mathrm{d} E / P-e w \cdot{ }^{18}$ Panel B of presents the Fama-MacBeth regression results. The results are similar to those in Panel A: the coefficients on lagged industry-aggregated analyst recommendations are positive and significant for all five specifications. We continue to find that changes in industry-aggregated analyst recommendations significantly predict one-quarter-ahead industry aggregate earnings changes. These results suggest that analyst recommendations contain information about future earnings at the industry level.

\subsection{Summary}

Overall, we provide modest evidence that changes in aggregate analyst recommendations contain information about future earnings at both the market and industry level. These results complement our earlier findings that aggregate analyst recommendations forecast aggregate returns. These results suggest an important channel through which aggregate analyst recommendations predict returns. ${ }^{19}$

\section{Conclusions}

Security analysts play an important role in financial markets by collecting, analyzing, and disseminating information. To date, the literature on analyst recommendations has focused primarily at the firm level and shows that analyst recommendations have information content. For example, Womack [1996] finds that upgrades (downgrades) in analyst recommendations are associated with positive (negative) abnormal returns around and after their announcements.

Our paper provides complementary evidence on the role of security analysts by examining the predictive content of aggregate analyst recommendations. We believe ours is the first paper to take this approach. Although the recommendations we study are made at the firm level, they might be based (implicitly or explicitly) in part on mar-

18. The results are unchanged when we use the two-way clustered standard errors. All coefficients on lagged industry-aggregated analyst recommendations are statistically significant at the 5 percent level.

19. Everything else equal, there should be a positive relation between returns and cash-flow news (Campbell [1991]). Kothari, Lewellen, and Warner [2006] document a (surprisingly) negative contemporaneous correlation between aggregate earnings and market returns for the period 19702000. They attribute this negative relation to the comovement between earnings and discount rates. However, Sadka and Sadka [2007] find that the aggregate earnings- market returns relation becomes positive after 2000. In unreported results, we confirm the results of Sadka and Sadka [2007] and find that the aggregate earnings are indeed positively related to market returns for our sample period 1994-2006. 
ket- or industry-level information. We thus examine whether changes in aggregate analyst recommendations are informative at the aggregate level, specifically, whether they have predictive content for future market and industry returns and earnings.

Using more than 350,000 sell-side analyst recommendations from 1994 to 2006, we construct a measure of change in aggregate recommendations at both the market and industry levels. We provide evidence that changes in aggregate analyst recommendations predict future market and industry returns. Moreover, we find that changes in aggregate analyst recommendations also predict future market and industry earnings growth. We conclude that analyst recommendations contain market- and industry-level information.

\section{References}

Ang, A., and G. Bekaert. "Stock Return Predictability: Is It There?" Review of Financial Studies 20 (2007): 651-707.

Anilowski, C., M. Feng, and D. Skinner. "Does Earnings Guidance Affect Market Returns? The Nature and Information Content of Aggregate Earnings Guidance." Journal of Accounting and Economics 44 (2007): 36-63.

Asquith, P., M. Mikhail, and A. Au. "Information Content of Equity Analyst Reports." Journal of Financial Economics 75 (2005): 245-282.

Baker, M., and J. Wurgler. "The Equity Share in New Issues and Aggregate Stock Returns." Journal of Finance 55 (2000): 2219-2257.

Baker, M., R. Taliaferro, and J. Wurgler. "Predictive Regressions Based on Managerial Decision Variables: Is There a Small-sample Bias?" Journal of Finance 61 (2006): 1711-1730.

Barber, B., R. Lehavy, M. McNichols, and B. Trueman. "Can Investors Profit from the Prophets? Security Analyst Recommendations and Stock Returns." Journal of Finance 56 (2001): 531-663.

Barber, B., R. Lehavy, M. McNichols, and B. Trueman. "Buys, Holds, and Sells: The Distribution of Investment Banks' Stock Ratings and the Implications for the Profitability of Analysts' Recommendations." Journal of Accounting and Economics 41 (2006): 87-117.

Boni, L., and K. Womack. "Analysts, Industries, and Price Momentum." Journal of Financial and Quantitative Analysis 41 (2006): 85-109.

Callen, J., O. HOPE, and D. SEGAL. “Domestic and Foreign Earnings, Stock Return Variability, and the Impact of Investor Sophistication." Journal of Accounting Research 43 (2005): 377-412.

Callen, J., and D. SEGAL. "Do Accruals Drive Stock Returns? A Variance Decomposition Analysis." Journal of Accounting Research 42 (2004): 527-560.

Campbell, J. "Stock Returns and the Term Structure." Journal of Financial Economics 18 (1987): $373-400$.

Campbell, J. “A Variance Decomposition for Stock Returns.” Economic Journal 101 (1991): 157-179.

Elton, E., M. Gruber, and S., Grossman. "Discrete Expectational Data and Portfolio Performance." Journal of Finance 41 (1986): 699-713.

Fama, E., and J. Macbeth. "Risk, Return, and Equilibrium: Empirical Tests." Journal of Political Economy 81 (1973): 60736.

Fama, E., and K. French. "Dividend Yields and Expected Stock Returns." Journal of Financial Economics 22 (1988): 3-25.

Fama, E., and K. French. "Business Conditions and Expected Returns on Stocks and Bonds." Journal of Financial Economics 25 (1989): 23-49.

Fama, E., and K. French. "Industry Costs of Equity." Journal of Financial Economics 43 (1997): 153-193.

Fama, E., and W. Schwert. "Asset Returns and Inflation." Journal of Financial Economics 5 (1977): 
115-146.

Gow, I., G. Ormazabal, and D. Taylor. "Correcting for Cross-sectional and Time-series Dependence in Accounting Research," Unpublished paper, Stanford University, 2008. Available at http://papers.ssrn.com/sol3/papers.cfm?abstract_id $=1175614$

Goyal, A., and, I. Welch. "A Comprehensive Look at the Empirical Performance of Equity Premium Prediction." Review of Financial Studies 21 (2008): 1455-1508.

Hecht, P., and T. Vuolteenaho. "Explain Returns with Cash-flow Proxies." Review of Financial Studies 19 (2006): 159-194.

Hirshleifer, D., K. Hou, and S. Teoh. “Accruals and Aggregate Stock Market Returns.” Forthcoming in Journal of Financial Economics, 2007.

Hodrick, R. “Dividend Yields and Expected Stock Returns: Alternative Procedures for Inference and Measurement." Review of Financial Studies 5 (1992): 357-386.

Jegadeesh, N., J. Kim, S. Krische, and C. Lee. "Analyzing the Analysts: When do Recommendations Add Value?" Journal of Finance 59 (2004): 1083-1124.

Keim, D., and R. Stambaugh. "Predicting Returns in the Stock and Bond Markets." Journal of Financial Economics 17 (1986): 357-390.

Kothari, S.P., J. Lewellen, and J. Warner. “Stock Returns, Aggregate Earnings Surprises and Behavioral Finance." Journal of Financial Economics 79 (2006): 537-568.

Lakonishok, J., and I. Lee. “Are Insider Trades Informative?" Review of Financial Studies 14 (2001): 79-111.

Lamont, O. “Earnings and Expected Returns.” Journal of Finance 53 (1998): 1563-1587.

Lander, J., A. Orphanides, and M. Douvoginnis. "Earnings Forecasts and the Predictability of Stock Returns: Evidence from Trading the S\&P 500." Journal of Portfolio Management, 23 (1997): 24-35.

Michaely, R., and K. Womack. "Market Efficiency and Biases in Brokerage Recommendations." Advances in Behavioral Finance II, edited by Richard Thaler, Chapter 11 (2005): 389-422.

Newey, W., and K. WEST. "A Simple, Positive Semi-definite, Heteroskedasticity and Autocorrelation Consistent Covariance Matrix." Econometrica 55 (1987): 703-708.

Park, C. "Stock Return Predictability and the Dispersion in Earnings Forecasts." Journal of Business, 78 (2005): 2351-2376.

Petersen, M. "Estimating Standard Errors in Finance Panel Data Sets: Comparing Approaches." Forthcoming in Review of Financial Studies, 2008.

Piotroski, J. D., and D. T. Roulstone.“The Influence of Analysts, Institutional Investors, and Insiders on the Incorporation of Market, Industry, and Firm-specific Information into Stock Prices." Accounting Review 79 (2004): 1119-1151.

Sadka, G. "Understanding Stock Price Volatility: The Role of Earnings." Journal of Accounting Research, 45 (2007): 199-228.

Sadka, G., and R. SADKA. "Predictability and the Earnings-returns Relation." Forthcoming in Journal of Financial Economics, 2007.

Seyhun, N. "The Information Content of Aggregate Insider Trading." Journal of Business 61 (1988): $1-24$.

Seyhun, N. “Why Does Aggregate Insider Trading Predict Future Stock Returns?" Quarterly Journal of Economics 107 (1992): 1303-1331.

Stambaugh, R. "Bias in Regressions with Lagged Stochastic Regressors," Unpublished Paper, University of Chicago, 1986.

Stambaugh, R. "Predictive Regressions." Journal of Financial Economics 54 (1999): 375421.

Stickel, S. "The Anatomy of the Performance of Buy and Sell recommendations." Financial Analysts Journal 51 (1995): 25-39.

Vuolteenaho, T. “What Drives Firm-level Stock Returns?” Journal of Finance 57 (2002): 233-264.

Womack, K. “Do Brokerage Analysts' Recommendations Have Investment Value?" Journal of Finance 51 (1996): 137-167. 